\title{
Benzyl bispidine as an efficient replacement for (-)-sparteine in ring opening polymerisationt
}

Cite this: Chem. Sci., 2013, 4, 1092

\author{
Richard Todd, ${ }^{a}$ Gabriel Rubio, ${ }^{\text {ab }}$ Daniel J. Hall, ${ }^{\text {a }}$ Sarah Tempelaar ${ }^{a}$ \\ and Andrew P. Dove*a
}

The synthesis and application of a dibenzyl-functionalized bispidine, in combination with 1-(3,5bis(trifluoromethyl)phenyl)-3-cyclohexylthiourea (TU) co-catalyst, has been demonstrated to be an excellent catalyst for the controlled ring-opening polymerisation (ROP) of lactide and cyclic carbonate monomers. Notably, the polymerisation proceeds with negligible transesterification or epimerisation, with the polymerisation of stereopure L-lactide affording highly crystalline poly(lactide) with a $T_{m}$ of 156 ${ }^{\circ} \mathrm{C}$. ROP of racemic lactide results in the observation of a modest degree of stereocontrol such that the probability of isotactic enchainment, $P_{\mathrm{m}}=0.74$. Comparison of a range of alternative hydrogen bond donor co-catalysts revealed that TU displayed the highest polymerisation rates in combination with the dibenzyl-functionalized bispidine.

Received 22nd November 2012 Accepted 12th December 2012 DOI: $10.1039 /$ c2sc22053a

www.rsc.org/chemicalscience

\section{Introduction}

The last decade has led to many advances in organocatalytic ring-opening polymerisation (ROP) of several cyclic monomers, most commonly including esters and carbonates. ${ }^{1-8}$ On account of their facile access, commercial availability and efficient nature, organic catalysts have become a valuable addition to this field. While several simple species have been reported to mediate these processes, 1,8-diazabicyclo[5.4.0]undec-7-ene (DBU), triazabicyclodecene (TBD) and $N$-heterocyclic carbenes are amongst the most active, ${ }^{9-14}$ the bifunctional catalyst system containing both a thiourea and tertiary amine (Fig. 1), has been<smiles>CN(C)C1CCCCC1NC(=S)Nc1cc(C(F)(F)F)cc(C(F)(F)F)c1</smiles>

1

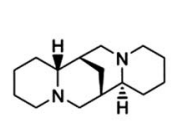

(-)-Sparteine

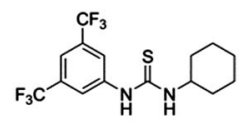

TU

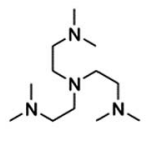

$\mathrm{Me}_{6}$ TREN

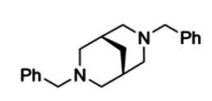

2
Fig. 1 Ring opening-polymerisation catalysts.

\footnotetext{
${ }^{a}$ Department of Chemistry, University of Warwick, Coventry, CV4 7AL, UK. E-mail: a.p. dove@warwick.ac.uk; Tel: +44(0)24 76524107

${ }^{b}$ University of Barcelona, Martí i Franquès Street, 1 08028, Barcelona, Spain

$\dagger$ Electronic supplementary information (ESI) available: Experimental details, NMR spectra, polymer tacticity analysis, thermal analysis and MALDI-ToF spectra. See DOI: 10.1039/c2sc22053a
}

reported to proceed with an almost absence of transesterification and epimerization side reactions, and thus provides a critical method for the production of precisely defined polymers. The high selectivity towards polymerisation in preference to deleterious side reactions is attributed to the supramolecular recognition (and concurrent activation) of the cyclic ester monomers in preference to the linear esters by the thiourea moiety. ${ }^{15,16}$ Critically however, it was demonstrated that the thiourea and the amine need not be conjoined and in turn this has led to the discovery of more active analogues, most notably the combination of 1-(3,5-bis(trifluoromethyl)phenyl)-3cyclohexylthiourea (TU) and (-)-sparteine, a naturally occurring alkaloid, which finds the optimum balance between activity and selectivity. ${ }^{16}$ The increased rate (25 fold increase) can be assigned to the two tertiary amines of $(-)$-sparteine being forced into close proximity as a consequence of the fixed rigid backbone with the lone pairs being oriented towards each other in such a way to promote hydrogen bonding. Concurrently, the weakly basic nature of $(-)$-sparteine $\left(\mathrm{p} K_{\mathrm{a}}=21.66\right),{ }^{17}$ maintains the high selectivity towards ROP $v s$. transesterification and epimerisation. This concept has since been extended to a wide range of hydrogen bond acceptors and donors that maintain the simultaneous activation of both the carbonyl group of the monomer and the initiating/propagating alcohol. ${ }^{18-22}$

In addition to its uses in ROP, (-)-sparteine has a number of other uses such as a chiral ligand in asymmetric deprotonations, substitutions and metalations. ${ }^{23-26}$ Despite this widespread use and utility, (-)-sparteine has become increasingly difficult to acquire through commercial sources. Several potential routes to obtain (-)-sparteine exist including isolation from the abundant Scotch Broom (Cytisus scoparius), ${ }^{27}$ or total synthesis via a multistep route that has varying overall yields. ${ }^{\mathbf{2 8 , 2 9}}$ Furthermore, 
the derivation of synthetic replacements may enable more highly active and stereoselective analogues to be realised.

These challenges to obtaining (-)-sparteine have led to the investigation of synthetically simple analogues. Aided by computational modelling, Hedrick and co-workers recently identified several commercially available tertiary amines that displayed similar nitrogen-nitrogen spacing $(\sim 3 \AA)$ and lone pair orientations to $(-)$-sparteine. ${ }^{30}$ of the tertiary amines selected, tris[2-dimethylamino)ethyl]amine ( $\left.\mathrm{Me}_{6} \mathrm{TREN}\right)$ and 1,4,7-trimethyl-1,4,7-triazacyclononane (TACN), in combination with TU, proved the most effective co-catalysts in the ROP of lactide. While TACN displayed comparable polymerization kinetics to (-)-sparteine, transesterification was noted to occur rapidly upon complete conversion of the monomer. Application of $\mathrm{Me}_{6}$ TREN led to better polymerisation control albeit at a slightly longer polymerisation time.

We hypothesised that a closer structural analogue to (-)-sparteine would lead to more comparable behaviour in ROP, and hence targeted the preparation of analogous bispidines. Herein we report the improved synthesis of a dibenzyl-functional bispidine, chosen for its identical backbone and similar basicity $\left(\mathrm{p} K_{\mathrm{a}}=21.25\right)$ to $(-)$-sparteine in addition to its apparent ease of synthesis, ${ }^{17}$ and explore its activity in the ROP of lactide, comparing directly to that of (-)-sparteine and $\mathrm{Me}_{6}$ TREN. Extension of the application of this species with a range of cocatalysts and other monomer feedstocks is also demonstrated.

\section{Results and discussion}

\section{Bispidine synthesis and lactide ROP}

The synthesis of benzyl bispidine has been reported previously by two different synthetic routes. While one route involves a double Mannich reaction of 1-benzyl-4-piperidone followed by a Wolff-Kishner reduction with hydrazine, ${ }^{31}$ on account of the broader substrate versatility, we preferred to apply the alternative four step synthetic route reported by Gogoll et al. starting from dimethyl malonate, 3 (Scheme 1). ${ }^{1732}$ Following the Knoevenagel condensation of $\mathbf{3}$ with paraformaldehyde, reduction of the resulting adduct using $\mathrm{LiAlH}_{4}$ yielded the tetraalcohol species, $\mathbf{5}$. Iodination of $\mathbf{5}$ as previously reported proved to be problematic on large scales and hence bromination with phosphorous tribromide was undertaken. ${ }^{33}$ The crude product could be readily purified by passing through a silica plug to obtain $6 \mathrm{~b}$ as a white solid in $61 \%$ yield. Reaction of $6 \mathbf{b}$ with excess benzyl amine enabled the isolation of pure bispidine, 2 ,

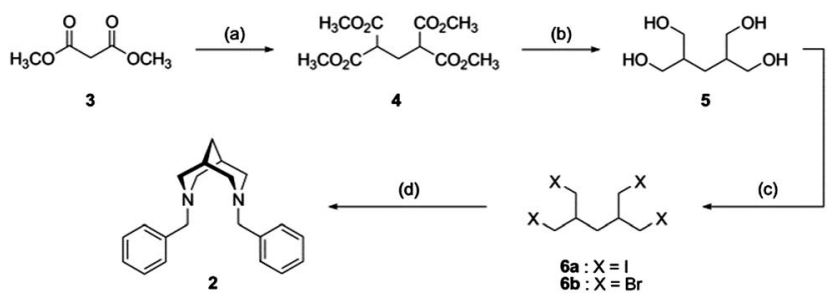

Scheme 1 Benzyl bispidine synthesis. (a) Paraformaldehyde, $\mathrm{KOH}, 95{ }^{\circ} \mathrm{C}$; (b) $\mathrm{LiAlH}_{4}, \mathrm{THF}$; (c) 6a: $\mathrm{I}_{2}, \mathrm{P}_{\text {red }}, 120^{\circ} \mathrm{C} ; \mathbf{6 b}: \mathrm{PBr}_{3}, 100{ }^{\circ} \mathrm{C}$; (d) benzylamine, toluene, reflux. after flash column chromatography using a selective gradient solvent system.

The ROP of L-lactide, LA, using $10 \mathrm{~mol} \%$ TU and 5 mol\% 2, was studied in $\mathrm{CDCl}_{3}\left([\mathrm{LA}]_{0}=0.7 \mathrm{M}\right)$ at ambient temperature using 1-phenylethanol as the initiator at a monomer-to-initiator ratio of $50\left([\mathrm{M}]_{0} /[\mathrm{I}]_{0}=50\right)$. Monitoring the polymerisation by ${ }^{1} \mathrm{H}$ NMR spectroscopy revealed that it had reached $87 \%$ monomer conversion after only $81 \mathrm{~min}$. Analysis of the resultant polymer by gel-permeation chromatography (GPC) revealed a number average molecular weight $\left(M_{\mathrm{n}}\right)$ of $13.4 \mathrm{~kg} \mathrm{~mol}{ }^{-1}$ with a narrow dispersity $\left(\bigoplus_{M}=1.08\right)$. Under the same conditions, polymerisation of L-LA with (-)-sparteine and $\mathrm{Me}_{6}$ TREN in place of 2 reached $93 \%$ and $92 \%$ monomer conversion after 66 and 450 min respectively with similar molecular parameters for the resulting PLA observed by GPC analysis (Table 1). To more precisely compare catalyst reactivities, kinetic studies of LA ROP for each catalyst system were investigated in triplicate (Fig. 2). First order kinetic plots of $\ln \left([\mathrm{M}]_{\mathrm{o}} /[\mathrm{M}]_{\mathrm{t}}\right)$ against time reveal a linear correlation, with apparent rate constants $\left(K_{\text {app }}\right)$ calculated as $1.35 \mathrm{~h}^{-1}, 2.53 \mathrm{~h}^{-1}$ and $0.38 \mathrm{~h}^{-1}$ for $2,(-)$-sparteine and $\mathrm{Me}_{6}$ TREN in combination with TU respectively. Under these conditions, while the bispidine catalyses lactide ROP at a lower rate than (-)-sparteine, the polymerisation occurs almost four times faster then when $\mathrm{Me}_{6}$ TREN is applied.

Table 1 Comparison of PLLA synthesised using various tertiary amines

\begin{tabular}{llllll}
\hline Catalyst $^{a}$ & $\begin{array}{l}\text { Conversion }^{b} \\
(\%)\end{array}$ & $\begin{array}{l}\text { Time } \\
(\mathrm{min})\end{array}$ & $\begin{array}{l}M_{\mathrm{n}}{ }^{c} \\
\left(\mathrm{~g} \mathrm{~mol}^{-1}\right)\end{array}$ & $\emptyset_{\mathrm{M}}{ }^{c}$ & $\begin{array}{l}K_{\text {app }} \\
\left(\mathrm{h}^{-1}\right)\end{array}$ \\
\hline (-)-Sparteine & 93 & 66 & 14900 & 1.08 & 2.53 \\
2 & 87 & 81 & 13400 & 1.08 & 1.35 \\
Me $_{6}$ TREN & 92 & 450 & 12100 & 1.09 & 0.38
\end{tabular}

${ }^{a}$ Conditions: $1 \mathrm{ml}$ of $\mathrm{CDCl}_{3}$ at room temperature; [L-LA] $=0.7 \mathrm{M}$; 1 phenylethanol as initiator; 5 mol\% tertiary amine; $10 \mathrm{~mol} \%$ of TU; $[\mathrm{M}]_{\mathrm{o}} /[\mathrm{I}]_{\mathrm{o}}=50 .{ }^{b}$ Determined by ${ }^{1} \mathrm{H}$ NMR spectroscopy. ${ }^{c}$ Determined by GPC analysis in $\mathrm{CHCl}_{3}$.

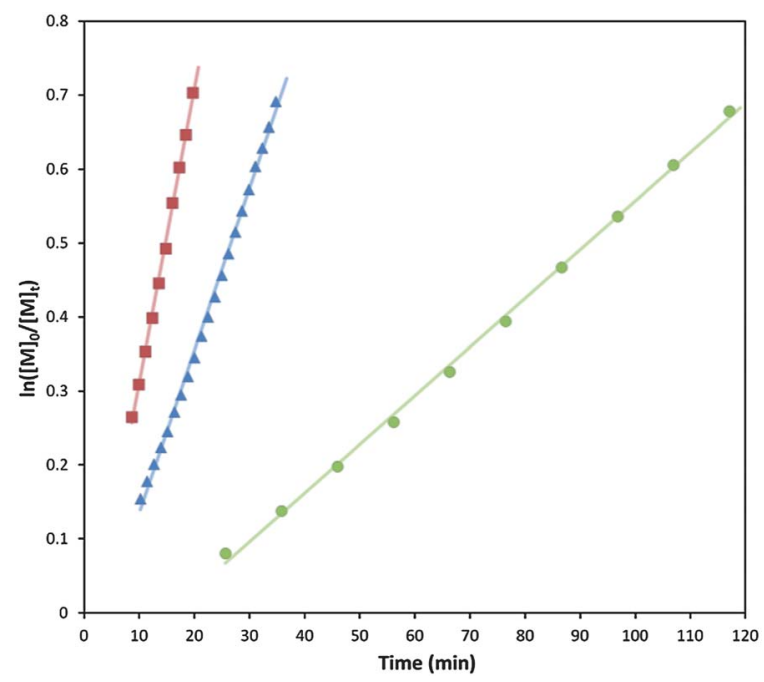

Fig. 2 Semi-log kinetic plot for the ROP of L-LA using TU in combination with a tertiary amine cocatalyst. (Red $=(-)$-sparteine; blue $=\mathbf{2}$; green $=\mathrm{Me}_{6} \mathrm{TREN}$ ). 
The controlled nature of the benzyl bispidine-catalysed polymerisation was further verified by the linear correlation between $M_{\mathrm{n}}$ values obtained by GPC and the monomer conversion determined by ${ }^{1} \mathrm{H}$ NMR spectroscopy (Fig. 3a) and the $[\mathrm{M}] /[\mathrm{I}]$ ratio (Fig. $3 \mathrm{~b}$ ). The resultant PLAs all displayed narrow dispersities (1.18-1.03, Table 2) which indicates that minimal transesterification is occurring. Further analysis of the resultant polymers by matrix-assisted laser desorption ionisation time of flight mass spectrometry (MALDI-ToF MS) revealed only single distributions with spacings of $144 \mathrm{~m} / \mathrm{z}$ between neighbouring peaks (Fig. 4). The absence of a second distribution with spacings of $72 \mathrm{~m} / \mathrm{z}$ is consistent with the absence of transesterification side reactions.

Thermal analysis of PLLAs with a degree of polymerisation (DP) of 100 synthesised using TU with both 2 and (-)-sparteine observed a melting temperature, $T_{\mathrm{m}}$, of 156 and $158{ }^{\circ} \mathrm{C}$ respectively. These match the previously reported melting points for isotactic PLLA prepared using (-)-sparteine. ${ }^{34,35}$ In combination with the observation of a singlet resonance in both the homonuclear decoupled ${ }^{1} \mathrm{H}$ NMR and ${ }^{13} \mathrm{C}$ NMR spectra of PLLA synthesised in this manner, these observations confirm the absence of stereo errors, and hence an absence of epimerisation, with identical levels resulting from both (-)-sparteine and 2 catalysed polymerisations. ${ }^{36-39}$

ROP of rac-lactide was undertaken to determine if any stereoselectivity would be observed using the catalyst combination of TU and 2. Despite the absence of stereogenic centres in 2, unlike (-)-sparteine, analysis of a DP100 poly(rac-lactide) by homonuclear decoupled ${ }^{1} \mathrm{H}$ NMR spectroscopy enabled the calculation of the probability of isotactic enchainment, $P_{\mathrm{m}}$, to be 0.74 , clearly demonstrating a preference to produce isotactic PLA from the racemic monomer mixture. This is comparable to that observed for rac-LA ROP with (-)-sparteine-TU which resulted in a $P_{\mathrm{m}}=0.74$ (literature value: $\left.P_{\mathrm{m}}=0.77\right) .{ }^{16}$
Table 2 Variation in $[\mathrm{M}]_{0} /[\mathrm{l}]_{0}$ with the $2-\mathrm{TU}$ binary catalyst system ${ }^{a}$

\begin{tabular}{llccc}
\hline$[\mathrm{M}] /[\mathrm{I}]$ & Conversion $^{b}(\%)$ & Time $(\mathrm{min})$ & $M_{\mathrm{n}}{ }^{c}\left(\mathrm{~g} \mathrm{~mol}^{-1}\right)$ & $D_{\mathrm{M}}{ }^{c}$ \\
\hline 10 & 90 & 21 & 3280 & 1.18 \\
20 & 94 & 43 & 6050 & 1.09 \\
50 & 92 & 75 & 13200 & 1.08 \\
100 & 89 & 137 & 26150 & 1.06 \\
250 & 90 & 366 & 61600 & 1.03
\end{tabular}

${ }^{a}$ Conditions: $\mathrm{CDCl}_{3}$; room temperature; $[\mathrm{L}-\mathrm{LA}]=0.7 \mathrm{M}$; 1-phenylethanol as initiator; $5 \mathrm{~mol} \%$ of $2 ; 10 \mathrm{~mol} \%$ of TU. ${ }^{b}$ Determined by ${ }^{1} \mathrm{H}$ NMR spectroscopy. ${ }^{c}$ Determined by GPC analysis in $\mathrm{CHCl}_{3}$.

\section{Variation of the hydrogen bond donor co-catalyst}

Several hydrogen bond donor alternatives to the thiourea cocatalyst (TU) have been reported over recent years that are successfully used in conjunction with (-)-sparteine (Fig. 5). ${ }^{18-22}$ In order to assess the efficiency of these co-catalysts in

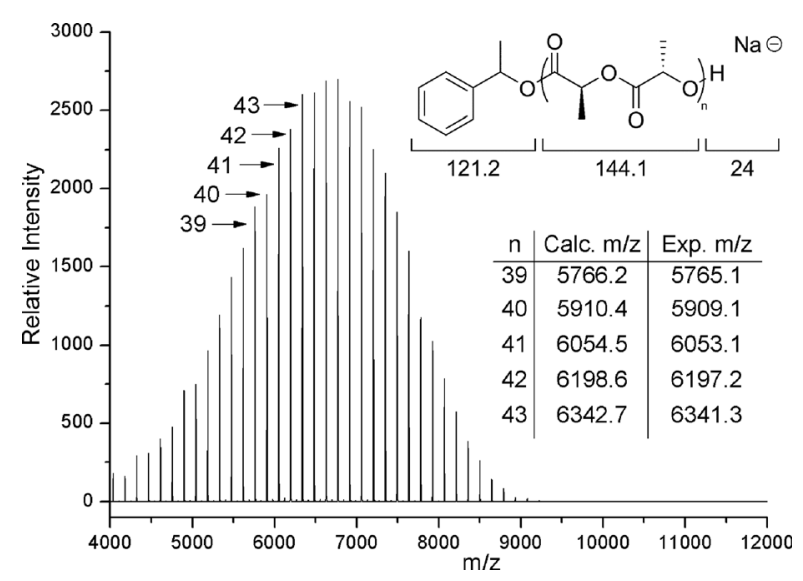

Fig. 4 MALDI-ToF MS spectrum of PLLA synthesised using the 2-TU binary catalyst system.
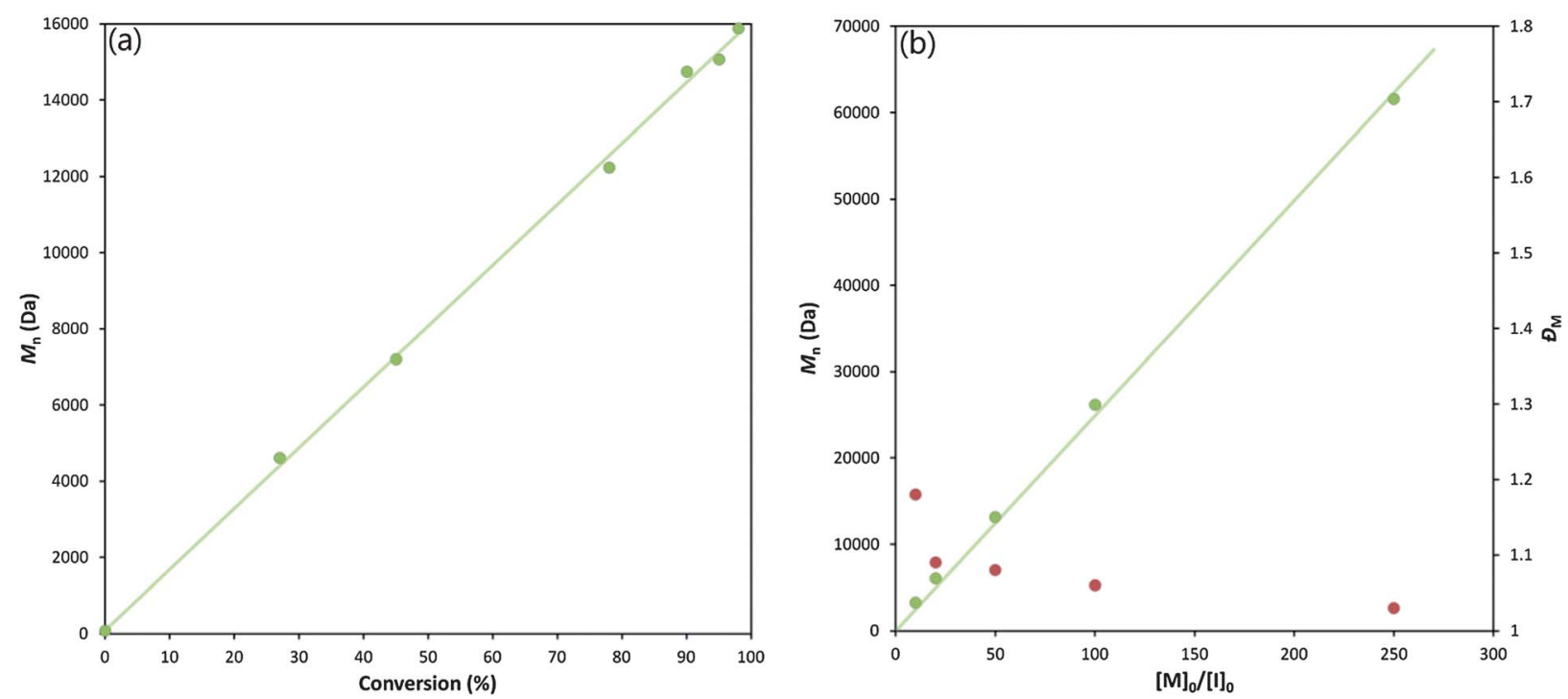

Fig. 3 (a) Number-average molecular weight $\left(M_{n}\right)$ against \% monomer conversion and (b) number-average molecular weight $\left(M_{n}\right)$ and dispersity $\left(\Theta_{M}\right)$ against initial monomer-to-initiator ratio $\left([\mathrm{M}]_{0} /[\mathrm{I}]_{0}\right)$ for the ROP of L-LA using TU and $\mathbf{2}$. 
<smiles>O=S(=O)(Nc1ccccc1)c1cccc(S(=O)(=O)Nc2ccccc2)c1</smiles><smiles>OC(F)(F)c1cccc(C(F)(F)C(F)(F)F)c1</smiles><smiles>Oc1cc(C(F)(F)F)cc(C(F)(F)F)c1</smiles><smiles>CN(C)CCNC(=S)Nc1cc(C(F)(F)F)cc(C(F)(F)F)c1</smiles>

10

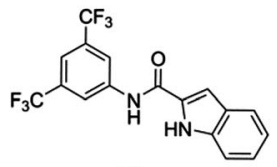

11

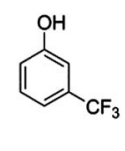

12

Fig. 5 Hydrogen bond donor co-catalysts

conjunction with the dibenzyl-functional bispidine, 2, in comparison to the initially reported system, we studied their activity for the ROP of L-lactide.

The ROP of L-lactide, LA, using $5 \mathrm{~mol} \% 2$ with $10 \mathrm{~mol} \%$ hydrogen bond donor co-catalyst was again studied in $\mathrm{CDCl}_{3}$ $\left([\mathrm{LA}]_{0}=0.7 \mathrm{M}\right)$ at ambient temperature using 1-phenylethanol as the initiator at a monomer-to-initiator ratio of $50\left([\mathrm{M}]_{0} /[\mathrm{I}]_{0}=\right.$ 50). The limited solubility of $\mathbf{1 1}$ in chloroform required its application at the lower molar ratio of $5 \mathrm{~mol} \%$ (in preference to the standard $10 \mathrm{~mol} \%$ ). To provide an accurate comparison, polymerisations using co-catalyst $\mathrm{TU}$ were also undertaken at 5 mol\% loading. Kinetic studies for each catalyst system were investigated in triplicate by monitoring monomer conversion against time using ${ }^{1} \mathrm{H}$ NMR spectroscopy. First order kinetic plots of $\ln \left([\mathrm{M}]_{0} /[\mathrm{M}]_{\mathrm{t}}\right)$ against time (Fig. 6) enabled the determination of $K_{\text {app }}$ values (Table 3). The tested catalysts demonstrated a broad range of activities, with $K_{\text {app }}$ values ranging from $1.35 \mathrm{~h}^{-1}$ to $0.03 \mathrm{~h}^{-1}$. While TU at $10 \mathrm{~mol} \%$ loading resulted in the most rapid polymerisation, the alternative co-catalysts were observed to display much lower $K_{\text {app }}$ values such that the second most active co-catalyst is $m$-trifluoromethylphenol, $\mathbf{1 2}$ with a $K_{\text {app }}$ approximately an order of magnitude lower than that observed for TU. Notably the amide catalyst 11 ( 5 mol\% loading) remained highly active with the measured $K_{\text {app }}$ value approximately 6 times lower than that TU at the reduced $5 \mathrm{~mol} \%$ loading. Polymerisation using co-catalyst 7 displayed extremely low reaction rate under these conditions, with $<5 \%$ monomer conversion being observed after one week.

In each case, analysis of the molecular parameters of the resultant polymers revealed low dispersity values which suggests that the polymerisations were well controlled (Table 3).

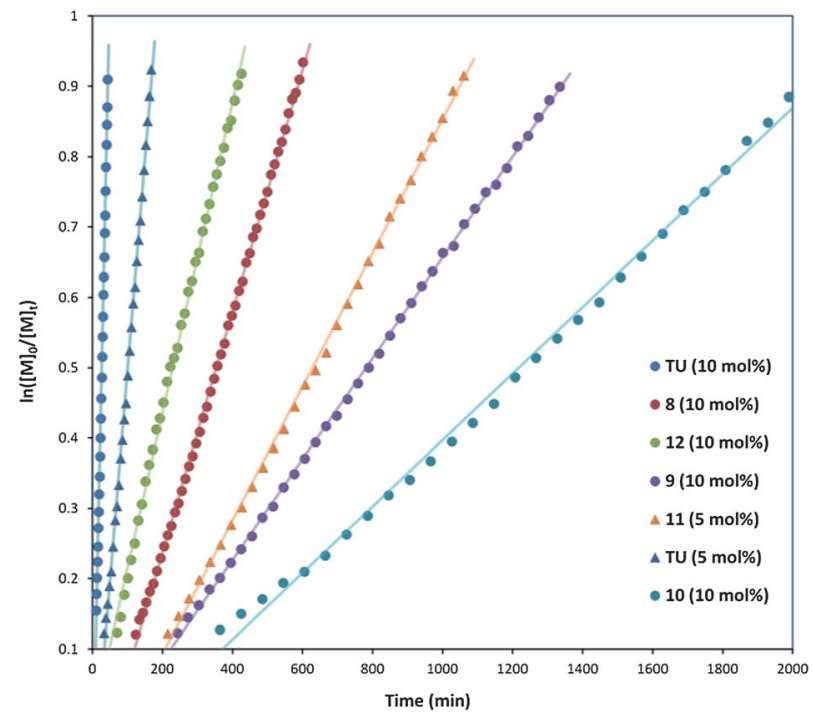

Fig. 6 Kinetic plots resulting from variation in hydrogen bond donor.

Notably however, co-catalyst $\mathbf{1 2}$ resulted in PLLA with lower molecular weight than predicted from the $[\mathrm{M}]_{0} /[\mathrm{I}]_{0}$ ratio. MALDI-ToF MS analysis of this polymer revealed two distinct distributions, both displaying the expected $144 \mathrm{~m} / \mathrm{z}$ spacing for the monomer repeat unit. A molecular weight difference of $\sim 40$ $\mathrm{m} / \mathrm{z}$ was observed between the distributions. One of these distributions revealed values that correspond to sodiumcharged polymer chains initiated from 1-phenylethanol as expected, however the other distribution showed values revealed values that correspond to sodium-charged polymer chains initiated from the co-catalyst 12, which possibly contributes to the increased observed rate of polymerisation. In the case of 9 , in which two $\mathrm{CF}_{3}$ substituents are present on the phenol ring, co-catalyst initiation was not observed which suggests that the phenol in $\mathbf{9}$ is appropriately activated to only undertake hydrogen bonding and not serve as a source of initiation in the polymerisation.

Interestingly, ${ }^{1} \mathrm{H}$ NMR spectroscopic analysis of the polymer produced using $\mathbf{2} / \mathbf{8}$ as co-catalysts for the ROP of L-LA revealed a number of overlapping quartets in the range of 5.10-5.25 ppm, consistent with the epimerisation of the monomer during the polymerisation. Despite the previous report of the ROP of L-LA using (-)-sparteine/8 proceeding in the absence of

Table 3 Variation in hydrogen bond donor co-catalyst

\begin{tabular}{|c|c|c|c|c|c|c|}
\hline Co-Catalyst & {$[\mathrm{M}] /[\mathrm{I}]$} & Conversion $^{c}(\%)$ & Time (min) & $M_{\mathrm{n}}{ }^{d}\left(\mathrm{~g} \mathrm{~mol}^{-1}\right)$ & ${D_{M}}^{d}$ & $K_{\text {app }}\left(\mathrm{h}^{-1}\right)$ \\
\hline $\mathrm{TU}^{a}$ & 50 & 86 & 75 & 13500 & 1.08 & $1.354 \pm 0.053$ \\
\hline $\mathrm{TU}^{b}$ & 50 & 90 & 350 & 12750 & 1.07 & $0.391 \pm 0.027$ \\
\hline $9^{a}$ & 50 & 91 & 3240 & 9090 & 1.11 & $0.044 \pm 0.002$ \\
\hline $10^{a}$ & 50 & 86 & 4200 & 10300 & 1.08 & $0.029 \pm 0.001$ \\
\hline $11^{b}$ & 50 & 92 & 2710 & 11900 & 1.08 & $0.063 \pm 0.007$ \\
\hline
\end{tabular}

${ }^{a}$ Conditions: $1 \mathrm{ml}$ of $\mathrm{CDCl}_{3}$ at room temperature; [L-LA] $=0.7 \mathrm{M} ; 5 \mathrm{~mol} \%$ 2; $10 \mathrm{~mol} \%$ co-catalyst; 1 -phenylethanol as initiator. ${ }^{b}$ Conditions: 1 ml of $\mathrm{CDCl}_{3}$ at room temperature; [L-LA] $=0.7 \mathrm{M} ; 5 \mathrm{~mol} \%$ 2; $5 \mathrm{~mol} \%$ co-catalyst; 1 -phenylethanol as initiator. ${ }^{c}$ Determined by ${ }^{1} \mathrm{H}$ NMR spectroscopy.

${ }^{d}$ Determined by GPC analysis in $\mathrm{CHCl}_{3}$. 
Table 4 Comparison of catalysts for the ROP of cyclic carbonates

\begin{tabular}{|c|c|c|c|c|c|c|}
\hline Monomer & Catalyst & {$[\mathrm{M}]_{0} /[\mathrm{I}]_{0}$} & Conversion $^{c}(\%)$ & Time (min) & $M_{\mathrm{n}}\left(\mathrm{g} \mathrm{mol}^{-1}\right)$ & $\emptyset_{M}$ \\
\hline $\mathrm{TMC}^{a}$ & 2 & 50 & 90 & 4750 & $9100^{d}$ & $1.03^{d}$ \\
\hline $\mathrm{MAC}^{b}$ & 2 & 20 & 90 & 410 & $6200^{e}$ & $1.10^{e}$ \\
\hline $\operatorname{MAC}^{b}$ & $\mathrm{Me}_{6}$ TREN & 20 & 89 & 45 days & $6100^{e}$ & $1.13^{e}$ \\
\hline
\end{tabular}

${ }^{a}$ Conditions: $0.5 \mathrm{ml}$ of $\mathrm{CDCl}_{3}$ at room temperature; [TMC] $=2.0 \mathrm{M} ; 5 \mathrm{~mol} \%$ tertiary amine; $5 \mathrm{~mol} \%$ TU; benzyl alcohol as initiator. ${ }^{b}$ Conditions: 0.5 $\mathrm{ml}$ of $\mathrm{CDCl}_{3}$ at room temperature; $[\mathrm{MAC}]=0.5 \mathrm{M} ; 5 \mathrm{~mol} \%$ tertiary amine; $10 \mathrm{~mol} \% \mathrm{TU}$; benzyl alcohol as initiator. ${ }^{c}$ Determined by ${ }^{1} \mathrm{H}$ NMR spectroscopy. ${ }^{d}$ Determined by GPC analysis in $\mathrm{CHCl}_{3} .{ }^{e}$ Determined by GPC analysis in DMF.

epimerisation, ${ }^{22}$ in our hands, comparable ${ }^{1} \mathrm{H}$ NMR spectra of the resultant polymers were also obtained for this system.

\section{ROP of cyclic carbonates}

To further investigate the versatility of the 2-TU binary catalyst system, polymerisations were undertaken of the 6-membered cyclic carbonates, trimethylene carbonate (TMC) and 5-methyl5-allyloxycarbonyl-1,3-dioxan-2-one (MAC) of which the (-)-sparteine-TU system has previously demonstrated well controlled homopolymerisation. ${ }^{40-42}$ Polymerisations were carried out under conditions published in literature, using both 2 and (-)-sparteine in combination with TU as catalysts with a target $[\mathrm{M}]_{0} /[\mathrm{I}]_{0}=50$ for TMC and 20 for MAC.

The ROP of TMC was performed using $5 \mathrm{~mol} \%$ of 2 or (-)-sparteine with $5 \mathrm{~mol} \% \mathrm{TU}$. After $c a .70 \mathrm{~h}{ }^{1} \mathrm{H}$ NMR spectroscopic analysis of the polymerisation mixtures revealed monomer conversions $>90 \%$ (Table 4). GPC analysis of the resultant poly(TMC)s showed similar $M_{\mathrm{n}}$ values resulted from polymerisations using both catalysts with narrow dispersities observed. MALDIToF analysis of the poly(TMC) synthesised using 2-TU revealed a single distribution having the desired spacing of $102 \mathrm{~m} / \mathrm{z}$. No secondary distributions were observed in the MALDI-ToF spectra.

The polymerisations of MAC were undertaken using $5 \mathrm{~mol} \%$ of 2 or (-)-sparteine with $10 \mathrm{~mol} \% \mathrm{TU}$, as recently reported. ${ }^{41}$ Targeting a DP of 20, polymerisations catalysed by $\mathrm{TU}$ in combination with 2 or (-)-sparteine achieved $90 \%$ monomer conversion after 410 and $400 \mathrm{~min}$ respectively. Notably these results demonstrate the comparable activity of both bispidine cocatalysts for the ROP of cyclic carbonates. In both cases, GPC analysis revealed that the molecular weights and dispersities for the resulting poly(MAC) were within error and MALDI-ToF MS analysis revealed only the desired single distribution with the predicted spacing of $200 \mathrm{~m} / \mathrm{z}$ that corresponds to the molecular weight of the repeat unit. Interestingly, the application of $10 \mathrm{~mol}$ $\%$ TU with $5 \mathrm{~mol} \% \mathrm{Me}_{6}$ TREN revealed a slower polymerization such that $89 \%$ conversion was recorded after 45 days. GPC analysis of the resultant polymer revealed molecular weights and dispersities in close agreement to (-)-sparteine and 2.

\section{Conclusions}

In this paper we demonstrate that, in conjunction with a hydrogen bond donor co-catalyst, the dibenzyl-functional bispidine, 2, is an excellent replacement for (-)-sparteine in the
ROP of lactide, producing well controlled polymers in the absence of observable transesterification and epimerisation. Additionally the ROP of rac-lactide revealed similar stereoselectivities for 2 and (-)-sparteine, with a $P_{\mathrm{m}}$ of 0.74 calculated for both catalyst systems. Optimisation of the co-catalyst revealed that 1-(3,5-bis(trifluoromethyl)phenyl)-3-cyclohexylthiourea (TU) resulted in the highest observed polymerisation rates. In addition, the ROP of cyclic carbonates with 2 was explored achieving rates almost identical to those observed using (-)-sparteine whilst the control over the molecular weight and dispersity was maintained. In conclusion, benzyl bispidine has proven to be a versatile catalyst and an excellent replacement for (-)-sparteine.

\section{Acknowledgements}

The Research Councils UK (RCUK) are acknowledged for funding a fellowship to A.P.D. We gratefully acknowledge financial support from EPSRC for funding a DTA studentship (R.T.) and a postdoctoral fellowship to D.J.H. (EP/H034420/1) as well as the purchase of the Bruker Ultraflex MALDI-ToF MS instrument. The ERASMUS programme is acknowledged for funding to support G.R. The GPC and thermal analysis equipment used in this research was obtained through Birmingham Science City: Innovative Uses for Advanced Materials in the Modern World (West Midlands Centre for Advanced Materials Project 2), with support from Advantage West Midlands (AWM) and part funded by the European Regional Development Fund (ERDF). Purac are gratefully acknowledged for the kind donation of lactide monomers, Aldrich Materials Science are thanked for donation of starting materials and Dr Ivan Prokes is thanked for assistance with NMR spectroscopic measurements.

\section{Notes and references}

1 D. Bourissou, S. Moebs-Sanchez and B. Martin-Vaca, C. $R$. Chim., 2007, 10, 775-794.

2 N. E. Kamber, W. Jeong, R. M. Waymouth, R. C. Pratt, B. G. G. Lohmeijer and J. L. Hedrick, Chem. Rev., 2007, 107, 5813-5840.

3 M. K. Kiesewetter, E. J. Shin, J. L. Hedrick and R. M. Waymouth, Macromolecules, 2010, 43, 2093-2107.

4 J. M. Becker, R. J. Pounder and A. P. Dove, Macromol. Rapid Commun., 2010, 31, 1923-1937.

5 A. P. Dove, ACS Macro Lett., 2012, 1, 1409-1412. 
6 O. Coulembier, P. Degée, J. L. Hedrick and P. Dubois, Prog. Polym. Sci., 2006, 31, 723-747.

7 G. Rokicki, Prog. Polym. Sci., 2000, 25, 259-342.

8 S. Tempelaar, L. Mespouille, O. Coulembier, P. Dubois and

A. P. Dove, Chem. Soc. Rev., 2013, DOI: 10.1039/c2cs35268k.

9 E. F. Connor, G. W. Nyce, M. Myers, A. Mock and J. L. Hedrick, J. Am. Chem. Soc., 2002, 124, 914-915.

10 A. P. Dove, H. B. Li, R. C. Pratt, B. G. G. Lohmeijer, D. A. Culkin, R. M. Waymouth and J. L. Hedrick, Chem. Commun., 2006, 2881-2883.

11 A. P. Dove, R. C. Pratt, B. G. G. Lohmeijer, D. A. Culkin, E. C. Hagberg, G. W. Nyce, R. M. Waymouth and J. L. Hedrick, Polymer, 2006, 47, 4018-4025.

12 B. G. G. Lohmeijer, R. C. Pratt, F. Leibfarth, J. W. Logan, D. A. Long, A. P. Dove, F. Nederberg, J. Choi, C. Wade, R. M. Waymouth and J. L. Hedrick, Macromolecules, 2006, 39, 8574-8583.

13 R. C. Pratt, B. G. G. Lohmeijer, D. A. Long, R. M. Waymouth and J. L. Hedrick, J. Am. Chem. Soc., 2006, 128, 4556-4557.

14 M. Fevre, J. Pinaud, A. Leteneur, Y. Gnanou, J. Vignolle, D. Taton, K. Miqueu and J. M. Sotiropoulos, J. Am. Chem. Soc., 2012, 134, 6776-6784.

15 A. P. Dove, R. C. Pratt, B. G. G. Lohmeijer, R. M. Waymouth and J. L. Hedrick, J. Am. Chem. Soc., 2005, 127, 13798-13799.

16 R. C. Pratt, B. G. G. Lohmeijer, D. A. Long, P. N. P. Lundberg, A. P. Dove, H. B. Li, C. G. Wade, R. M. Waymouth and J. L. Hedrick, Macromolecules, 2006, 39, 7863-7871.

17 L. Toom, A. Kutt, I. Kaljurand, I. Leito, H. Ottosson, H. Grennberg and A. Gogoll, J. Org. Chem., 2006, 71, 71557164.

18 C. Thomas, F. Peruch, A. Deffieux, A. Milet, J. P. Desvergne and B. Bibal, Adv. Synth. Catal., 2011, 353, 1049-1054.

19 S. Koeller, J. Kadota, A. Deffieux, F. Peruch, S. Massip, J. M. Leger, J. P. Desvergne and B. Bibal, J.Am. Chem. Soc., 2009, 131, 15088-15089.

20 S. Koeller, J. Kadota, F. Peruch, A. Deffieux, N. Pinaud, I. Pianet, S. Massip, J. M. Leger, J. P. Desvergne and B. Bibal, Chem.-Eur. J., 2010, 16, 4196-4205.

21 A. Alba, A. Schopp, A. P. D. Delgado, R. Cherif-Cheikh, B. Martin-Vaca and D. Bourissou, J. Polym. Sci., Part A: Polym. Chem., 2010, 48, 959-965.

22 O. Coulembier, D. P. Sanders, A. Nelson, A. N. Hollenbeck, H. W. Horn, J. E. Rice, M. Fujiwara, P. Dubois and J. L. Hedrick, Angew. Chem., Int. Ed., 2009, 48, 5170-5173.
23 T. A. Johnson, M. D. Curtis and P. Beak, Org. Lett., 2002, 4, 2747-2749.

24 S. D. Wu, S. Lee and P. Beak, J. Am. Chem. Soc., 1996, 118, 715-721.

25 P. Oña-Burgos, I. Fernández, L. Roces, L. Torre-Fernández, S. García-Granda and F. López-Ortiz, Org. Lett., 2008, 10, 3195-3198.

26 C. Metallinos and V. Snieckus, Org. Lett., 2002, 4, 1935-1938.

27 P. M. Dewick, in Medicinal Natural Products, John Wiley \& Sons, Ltd, 2009, pp. 311-420.

28 J.-P. R. Hermet, M. J. McGrath, P. O'Brien, D. W. Porter and J. Gilday, Chem. Commun., 2004, 1830-1831.

29 N. R. Norcross, J. P. Melbardis, M. F. Solera, M. A. Sephton, C. Kilner, L. N. Zakharov, P. C. Astles, S. L. Warriner and P. R. Blakemore, J. Org. Chem., 2008, 73, 7939-7951.

30 D. J. Coady, A. C. Engler, H. W. Horn, K. M. Bajjuri, K. Fukushima, G. O. Jones, A. Nelson, J. E. Rice and J. L. Hedrick, ACS Macro Lett., 2012, 1, 19-22.

31 P. C. Ruenitz and E. E. Smissman, J. Heterocycl. Chem., 1976, 13, 1111-1113.

32 A. Gogoll, C. Johansson, A. Axén and H. Grennberg, Chem.Eur. J., 2001, 7, 396-403.

33 J. A. Landgrebe and L. W. Becker, J. Am. Chem. Soc., 1968, 90, 395-400.

34 G. M. Miyake and E. Y. X. Chen, Macromolecules, 2011, 44, 4116-4124.

35 L. Zhang, F. Nederberg, J. M. Messman, R. C. Pratt, J. L. Hedrick and C. G. Wade, J. Am. Chem. Soc., 2007, 129, 12610-12611.

36 J. Coudane, C. UstarizPeyret, G. Schwach and M. Vert, J. Polym. Sci., Part A: Polym. Chem., 1997, 35, 1651-1658.

37 J. E. Kasperczyk, Polymer, 1999, 40, 5455-5458.

38 M. J. Stanford and A. P. Dove, Chem. Soc. Rev., 2010, 39, 486494.

39 M. T. Zell, B. E. Padden, A. J. Paterick, K. A. M. Thakur, R. T. Kean, M. A. Hillmyer and E. J. Munson, Macromolecules, 2002, 35, 7700-7707.

40 F. Nederberg, B. G. G. Lohmeijer, F. Leibfarth, R. C. Pratt, J. Choi, A. P. Dove, R. M. Waymouth and J. L. Hedrick, Biomacromolecules, 2006, 8, 153-160.

41 S. Tempelaar, L. Mespouille, P. Dubois and A. P. Dove, Macromolecules, 2011, 44, 2084-2091.

42 D. M. Stevens, S. Tempelaar, A. P. Dove and E. Harth, ACS Macro Lett., 2012, 1, 915-918. 